\title{
Diversification of health-promoting phytochemicals in radish (Raphanus raphanistrum) and kale (Brassica oleracea) micro-greens using high light bio-fortification
}

\author{
Alukhanyo Xonti ${ }^{1}$, Ethan Hunter ${ }^{1}$, Nokwanda Kulu' ${ }^{1}$, Palesa Maboeei ${ }^{1}$, Marietjie \\ Stander $^{2}$, Jens Kossmann ${ }^{1}$, Shaun Peters ${ }^{1}$, Bianke Loedolff*1
}

${ }^{1}$ Institute for Plant Biotechnology, Department of Genetics, Faculty of AgriSciences, Stellenbosch University, Matieland, 7602, South Africa; ${ }^{2}$ Central Analytical Facilities, Stellenbosch University, Matieland, 7602, South Africa

*Corresponding author: Bianke Loedolff, PhD, Institute for Plant Biotechnology, Department of Genetics, Faculty of AgriSciences, Stellenbosch University, Matieland, 7602, South Africa

Submission Date: December 6 ${ }^{\text {th }}, 2019$; Acceptance Date: February 23 ${ }^{\text {rd }}$, 2020; Publication Date: February $28^{\text {th }}, 2020$

Citation: XontiA., Hunter E., Kulu N., Maboeei P., Stander M., Kossmann J., Peters S., Loedolff B. Diversification of health-promoting phytochemicals in radish (Raphanus raphanistrum) and kale (Brassica oleracea) micro-greens using high light bio-fortification. Functional Foods in Health and Disease 2020; 10(2): 65-81. DOI: https:/doi.org/10.31989/ffhd.v10i2.681

\begin{abstract}
Background: Fruits and vegetables contain significant amounts of biologically active phytochemicals (such as polyphenols, glucosinolates, phytoestrogens, and carotenoids, amongst others), which have associated with human health and nutrition. Numerous bio-fortification strategies are employed to enhance the nutritional profile of plant-based foods to address and minimize the severe outcomes of malnutrition.

Methods: Using an established high light-induced bio-fortification strategy, we aimed to augment the accumulation of health-promoting phytochemicals in a selection of Brassica micro-greens (kale and radish). High throughput tandem mass spectrometry was used to identify the differential accumulation of phytochemicals and subsequently determined their antioxidant capacity. Using a classical DNA protection assay, we demonstrated that human genomic DNA could be protected from oxidative stress.
\end{abstract}

Results: We report here on the potential link between the increased phytochemicals, total antioxidant, capacity and potential consequent role in human DNA protection.

Conclusion: Bio-fortification implemented as a future strategy could enhance the phytochemical profile and consequent antioxidant potential for the development of functional foods and food supplements. 
Keywords: antioxidant, bio-fortification, Brassica, DNA protection, high light, microgreens, phytochemicals

\section{BACKGROUND}

Basic nutrition is the cornerstone of good health and requires an adequate intake of foods rich in macro- (carbohydrates, proteins, and fats) and micro-nutrients (vitamins and minerals). Functional foods (foods that provide health benefits beyond basic nutrition) contain many biologically active compounds known to be positively associated to human health. These include terpenes [1, 2], polyphenols [3, 4], glucosinolates [5, 6], phytoestrogens $[7,8,9]$ and carotenoids $[10,11]$. Collectively termed phytochemicals, these biologically active compounds form part of a plant's secondary metabolite profile and often accumulate as part of global stress response (both abiotic and biotic) mechanisms [12, 13, 14].

Nutrition- and health-based research actively seeks specific compounds in the diet-disease relationship to guide consumers toward an optimal disease-prevention diet. Increasing evidence suggests that Brassica vegetables (also known as cruciferous vegetables) and leafy greens (including broccoli, kale, mustard greens, rocket, radish, cabbage, cauliflower amongst many others) are potentially effective at protecting against cardiovascular diseases and some cancers, owing to their high content of glucosinolates and isothiocyanates $[15,16]$. Despite Brassica species being well described to accumulate several other important phytochemicals as well, a sustained and diverse diet (Brassica-enriched) is required for health beneficial effects [17].

While all plants accumulate a diverse variety of phytochemicals, micro-greens (MGs, immature plants with 2-4 true leaves) hyper-accumulate phytochemicals (up to 100 times more than mature plant $[18,19]$. Consequently, MGs are generally considered nutritionally superior. The study of MGs is an emergent research field focused on their health and potential disease prevention benefits [20, 21]. As small edibles (with 2-6 true leaves), MGs are harvested 10-25 days after germination. During this adaptive growth stage, they accumulate substantial amounts of vitamins, minerals, and a diverse range of phytochemicals. Comparatively, older (environmentally adapted) plants do not display this enhanced nutritive profile and rely on alternate stress response pathways [22, 23, 24, 25, 26].

Brassica MGs have been very popular in the culinary world and often used for enhanced sensory purposes. More recently, several Brassica MGs have been recognised for their enriched phytochemical and nutritional qualities $[27,28]$. Consequently, the large number of vegetables required daily could be condensed into smaller dietary portions containing significantly more health beneficial phytochemicals. MGs serve as an ideal target for bio-fortification strategies whereby phytochemical profiles could be altered during plant growth, using abiotic environmental stress stimuli. Because these secondary metabolites accumulate as part of stress responsemechanisms, we demonstrate in this study the effectiveness of high light (HL) as a bio-fortification strategy to enhance the phytochemical profile of MGs for radish (Raphanus raphanistrum) and kale (Brassica oleracea), two commonly consumed Brassica species.

\section{MATERIALS AND METHODS}

\section{Plant material and growth conditions}

Radish and kale seeds (Raphanus raphanistrum subsp. sativus, Brassica oleracea var. sabellica) were obtained from a commercial seed supplier (Seeds for Africa, South Africa). Subsequent to 
stratification $\left(24 \mathrm{~h}, 4^{\circ} \mathrm{C}\right)$, plants were propagated to MG stage (2-6 true leaves) under (i) controlled growth conditions (16 h light, $70 \mu \mathrm{mol}$ photons $\mathrm{m}^{-2} \mathrm{~s}^{-1}, 22{ }^{\circ} \mathrm{C}, 8 \mathrm{~h}$ dark, $22{ }^{\circ} \mathrm{C}, 60 \%$ relative humidity) and (ii) high light intensity $\left(270 \mu \mathrm{mol}\right.$ photons $\left.\mathrm{m}^{-2} \mathrm{~s}^{-1}\right)$. All plants were maintained and propagated on peat disks (Jiffy ${ }^{\mathrm{TM}}$ no.7, South Africa).

\section{Total starch and metabolite extractions}

Total starch was extracted from whole, lyophilized MG tissue (50 mg) using the Total Starch HK Assay kit (Megazyme International Ireland Ltd.) and quantified using the online tool Mega-Calc ${ }^{\mathrm{TM}}$ software tool.

Metabolites were extracted with acetonitrile from whole, lyophilized MG tissue (300 mg), as previously described [18, 29]. Prior to further analysis, polyphenolic extracts were lyophilised and desalted as previously described (omitting the Polyklar AT; [30]).

\section{Ascorbic acid and antioxidant capacity measurements}

Ascorbic acid was quantified in lyophilised micro-green tissue $(500 \mathrm{mg}$ ) using an Ascorbic Acid Assay kit (MAK074, Sigma-Aldrich, South Africa), according to manufacturer's instructions. Similarly, total antioxidant capacity was determined on lyophilised, micro-green tissue (500 mg) as compared against a Trolox standard, using the Total Antioxidant Capacity Assay kit (MAK187, Sigma-Aldrich, South Africa), according to manufacturer's instructions.

\section{DNA damage assays}

DNA damage assays were performed as previously described [31]. Human genomic DNA (0.5 $\mu \mathrm{g} / \mu \mathrm{L}$; cat. no. 11691112 001, Roche, Sigma, South Africa) was diluted in phosphate buffer (50 $\mathrm{mM}, \mathrm{pH}$ 7.4) and damaged using Fenton's reagent ( $1 \mathrm{mM} \mathrm{FeSO}_{4}, 0.1 \mathrm{mM} \mathrm{H}_{2} \mathrm{O}_{2}$ ). Samples were subject to heat $\left(37^{\circ} \mathrm{C}, 30 \mathrm{~min}\right)$, and DNA damage analyz ed via electrophoresis ( $0.8 \%$ agarose). Damaged DNA was observed as a loss of integrity (smear). DNA protection was assessed by the addition of lyophilized MG extracts (diluted with water to concentrations of 1000, 100 and $10 / \mathrm{g}$ $\mathrm{ml}^{-1}$ ) prior to the addition of Fenton's reagent [31]. DNA protection was observed as retained integrity (no smear). Trolox, an analogue of vitamin E, was used as control.

\section{Tandem mass spectrometry (LC-MS/MS) analyses and phenolic compound identification}

LC-MS/MS analyses were performed, as previously described [18], with a Waters Synapt G2 quadrupole time-of-flight mass spectrometer (Waters Corporation, Milford, MA, USA) equipped with a Waters Acquity UPLC. Samples were separated on a Waters UPLC BEH C18 column (2.1 $\mathrm{x} 100 \mathrm{~mm} ; 1.7 \mu \mathrm{m}$ ) at a flow rate of $0.3 \mathrm{ml} / \mathrm{min}$ at $55{ }^{\circ} \mathrm{C}$. Solvent A consisted of $0.1 \%$ formic acid in water, and solvent $\mathrm{B}$ was $0.1 \%$ formic acid in acetonitrile. The mobile phase gradient was initiated at $100 \%$ solvent A for $1 \mathrm{~min}$ and linearly reduced to $28 \%$ solvent A over 22 min. Subsequently, the mobile phase was changed to $40 \%$ solvent B over 50 s followed by a wash step in $100 \%$ solvent $\mathrm{B}$ before the column was re-equilibrated to the initial conditions for $4 \mathrm{~min}$. Electrospray ionization was applied in the negative mode, and the scan range was either from $\mathrm{m} / \mathrm{z}$ 150-1500 (high collision energy scan) or $\mathrm{m} / \mathrm{z}$ 40-1500 (low collision energy scan). The photo diode array detector was set to scan from 220-600 nm. The capillary voltage was set at either $6 \mathrm{~V}$ (low collision energy scan from) or 30-60 V (high collision energy scan), the cone voltage was $15 \mathrm{~V}$, the source temperature $120^{\circ} \mathrm{C}$ and the desolvation temperature was $275^{\circ} \mathrm{C}$. The 
desolvation and cone gas (nitrogen) flows were $650 \mathrm{~L} / \mathrm{h}$ and $50 \mathrm{~L} / \mathrm{h}$, respectively. Sodium formate was used for calibration, and leucine encephalin was infused in the background as lock mass for accurate mass determinations. Metabolites were monitored using their deprotonated quasimolecular ions. Base peak chromatograms (extracted for NL and HL, respectively) were overlaid to identify the compounds that were differentially accumulating. Compounds were predicted using the Metabolomics workbench (www.metabolomicsworkbench.org; [32]). The database was searched, using the $\mathrm{m} / \mathrm{z}$ mass obtained from total ion chromatograms, with parameters set to the negative ion $[\mathrm{M}-\mathrm{H}]-$ mode and a mass tolerance of $+/-0.2 \mathrm{~m} / \mathrm{z}$. Tentative identification was based on the accurate mass and fragment ions of the specific peaks compared to literature.

\section{Statistical analyses}

All data acquired in this study are the results of three independent experiments, expressed as means \pm standard error. Statistical significance was determined by a two- tailed t-test $(p<0.055)$, using the control group (normal light) as a comparison. Statistical analysis was performed with GraphPad Prism (version 7.0).

\section{RESULTS}

High light induces structural adaptations, increases starch accumulation and alters the accumulation of ascorbic acid

Radish and kale, propagated to MG stage under HL conditions, displayed structural phenotypic responses when compared to normal light (NL) conditions (Figure 1).

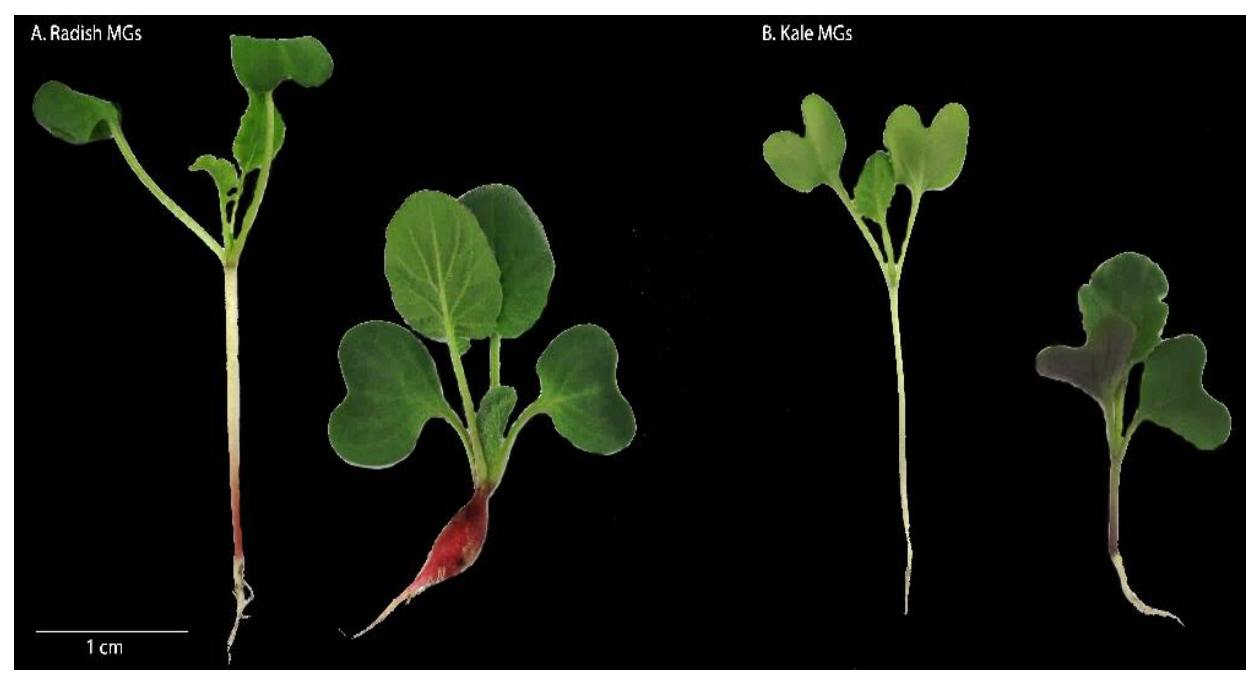

Figure 1: Comparison between phenotypic responses occurring in (A) radish and (B) kale MGs grown under HL. Phenotypic differences included stunted stem development, broader leaf surface area, purple coloration, and storage root development (the latter only applying to radish).

Both radish and kale MGs displayed stunted stem elongation and larger leaves under HL conditions when compared to NL conditions. The exposure to HL further induced purple coloration in the leaves of kale but not in radish. Radish MGs, however, showed the rapid development of storage roots. Total starch content increased significantly in both radish and kale MGs. Radish accumulated almost 9-fold higher total starch, under HL when compared to NL 
conditions (191.9 $\pm 30.1 \mathrm{mg} \mathrm{g}^{-1} \mathrm{DW}$ and $20.9 \pm 5.2 \mathrm{mg} \mathrm{g}^{-1} \mathrm{DW}$ for HL and NL, respectively; Figure 2). Kale accumulated almost 3-fold higher total starch, under HL when compared to NL conditions $\left(106.2 \pm 18.2 \mathrm{mg} \mathrm{g}^{-1} \mathrm{DW}\right.$ and $35.7 \pm 15.4 \mathrm{mg} \mathrm{g}^{-1} \mathrm{DW}$ for HL and NL, respectively; Figure 2). Ascorbic acid content decreased significantly in radish MGs, almost 3-fold lower, under HL when compared to NL conditions $\left(0.37 \pm 0.02 \mathrm{mg} \mathrm{g}^{-1} \mathrm{DW}\right.$ and $0.15 \pm 0.01 \mathrm{mg} \mathrm{g}^{-1} \mathrm{DW}$ for HL and NL, respectively; Figure 3). Ascorbic acid content did not change significantly in kale MGs $\left(0.04 \pm 0.03 \mathrm{mg} \mathrm{g}^{-1} \mathrm{DW}\right.$ and $0.09 \pm 0.01 \mathrm{mg} \mathrm{g}^{-1} \mathrm{DW}$ for HL and NL, respectively; Figure 3$)$.

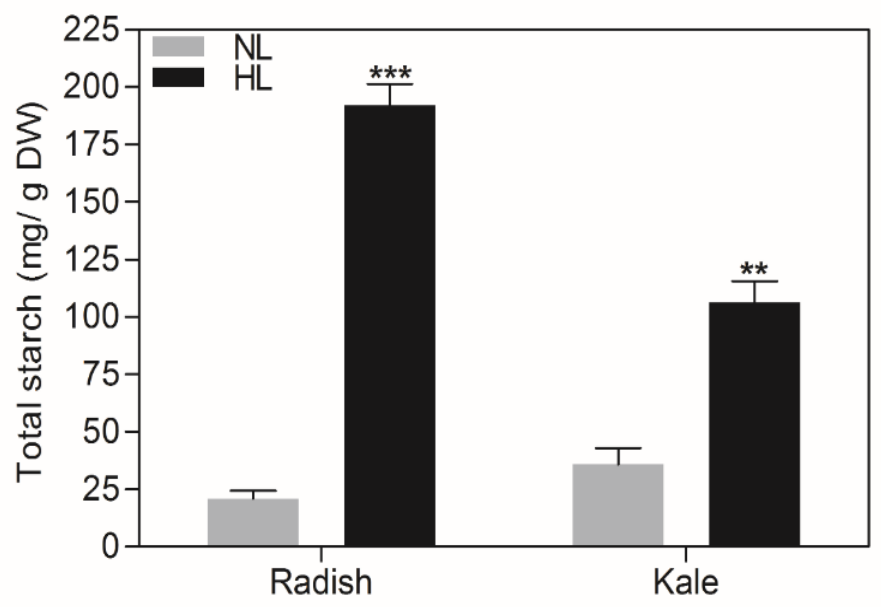

Figure 2: Total starch was compared between radish and kale MGs propagated under normal and high light conditions. Total starch content in lyophilized tissue was determined from three independent experiments, using pooled samples of micro-greens (approximately 200 plants per replicate). Statistical significance is indicated by stars as determined by a two tailed t-test, using $\mathrm{NL}$ as the comparison control (radish HL, **p $=0.0052$; kale HL, ***p $=0.0039$ ). NL, normal light; HL, high light.

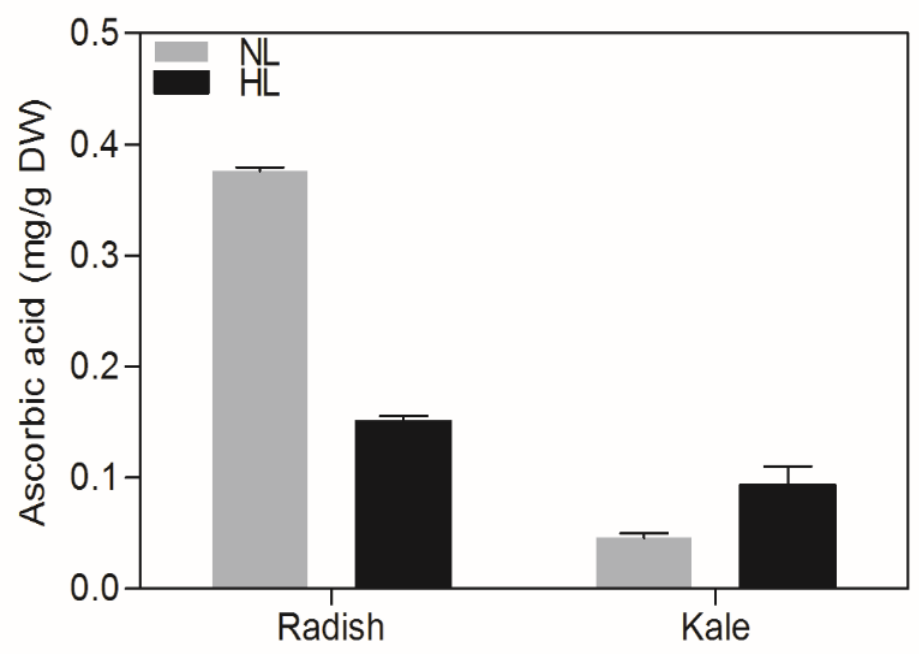

Figure 3: Accumulation of ascorbic acid was compared between radish and kale MGs propagated under normal and high light conditions. Ascorbic acid content in lyophilized tissue was determined from three independent experiments, using pooled samples of micro-greens (approximately 200 plants per replicate). Statistical significance is indicated by stars as determined 
by a two tailed t-test, using NL as the comparison control (radish HL ** $\mathrm{p} \leq 0.0012$; kale HL, $\mathrm{p}=$ 0.0741). NL, normal light; HL, high light.

\section{High light positively influences total antioxidant capacity}

Acetonitrile extracts from radish, and kale MGs were analyzed further for their total antioxidant capacity (TAC), expressed as Trolox (vitamin E) equivalents. The TAC increased significantly in extracts from both radish and kale MGs grown under HL when compared to NL. The TAC in extracts from radish MGs increased almost 1.7-fold under HL when compared to NL conditions (4.6 $\pm 0.6 \mathrm{mg} \mathrm{g}^{-1} \mathrm{DW}$ and $2.6 \pm 0.7 \mathrm{mg} \mathrm{g}^{-1} \mathrm{DW}$ for HL and NL, respectively; Figure 4). The TAC in extracts from kale MGs increased almost 2.5-fold under HL when compared to NL conditions $\left(9.2 \pm 1.8 \mathrm{mg} \mathrm{g}^{-1} \mathrm{DW}\right.$ and $3.6 \pm 0.5 \mathrm{mg} \mathrm{g}^{-1} \mathrm{DW}$ for HL and NL, respectively; Figure 4).

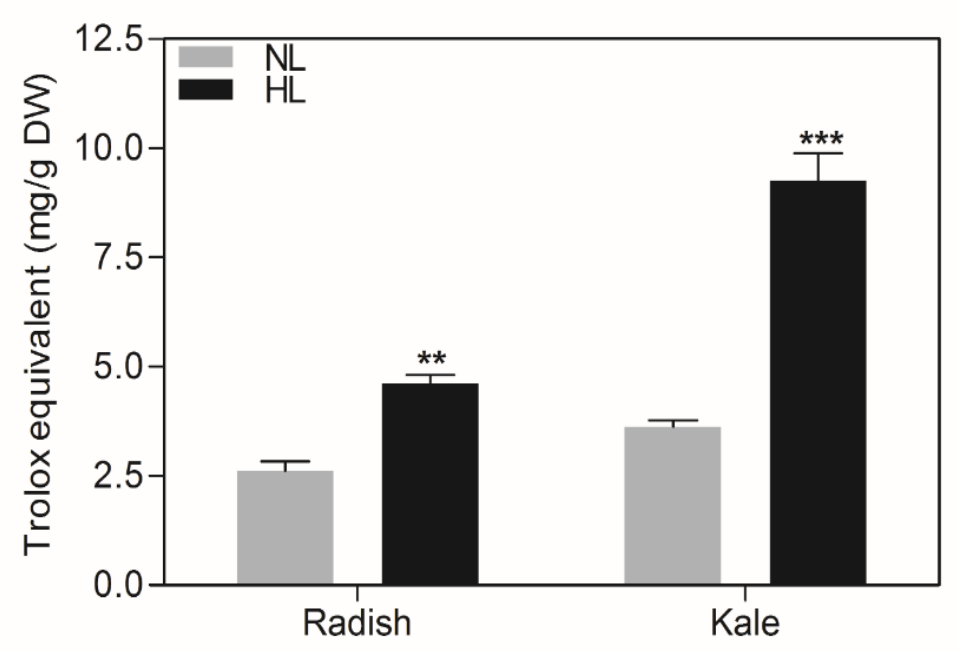

Figure 4: Total antioxidant capacity (TAC) was compared between radish and kale MGs propagated under normal and high light conditions. TAC in lyophilized tissue was determined from three independent experiments, using pooled samples of micro-greens (approximately 200 plants per replicate) and expressed as Trolox equivalents. Statistical significance is indicated by stars as determined by a two- tailed t-test, using NL as the comparison control (radish HL, **p $=0.0052$; kale HL, $* * * p=0.0008)$. NL, normal light; HL, high light.

DNA damage/protection assays on human genomic DNA were conducted using Fenton's reagent $\left(\mathrm{H}_{2} \mathrm{O}_{2}\right.$ induces oxidative stress $)$, in the presence and absence of various concentrations of MG extracts to assess whether extracts from radish and kale MGs were efficient as antioxidants (Figure 5). The DNA that was incubated without (no oxidative damage) or with Fenton's reagent (oxidative damage) and analyz ed using electrophoresis, with the DNA being visualised in an agarose gel as bright and intact (undamaged) or lighter smeared (damaged) bands, respectively. The DNA that was pre-incubated with extracts from radish and kale MGs (at concentrations of 1000, 100, and $10 \mathrm{~g} \mathrm{~g} \mathrm{ml}^{-1}$, respectively) and incubated with Fenton's reagent was assessed. No DNA protection was observed for the lowest concentration (both extracts, $10\left(\mathrm{~g} \mathrm{ml}^{-1}\right)$. Varying degrees of DNA protection was observed at higher concentrations (both extracts, 1000 and 100 $\left(\mathrm{g} \mathrm{ml}^{-1}\right)$. Comparatively, the extract from radish MGs grown under NL exhibited the greatest 
DNA protection at a concentration of $100\left(\mathrm{~g} \mathrm{ml}^{-1}\right.$. At concentrations of $1000 \mathrm{~g} \mathrm{ml}^{-1}$ extracts from both radish and kale under NL and HL exhibited DNA protection abilities.

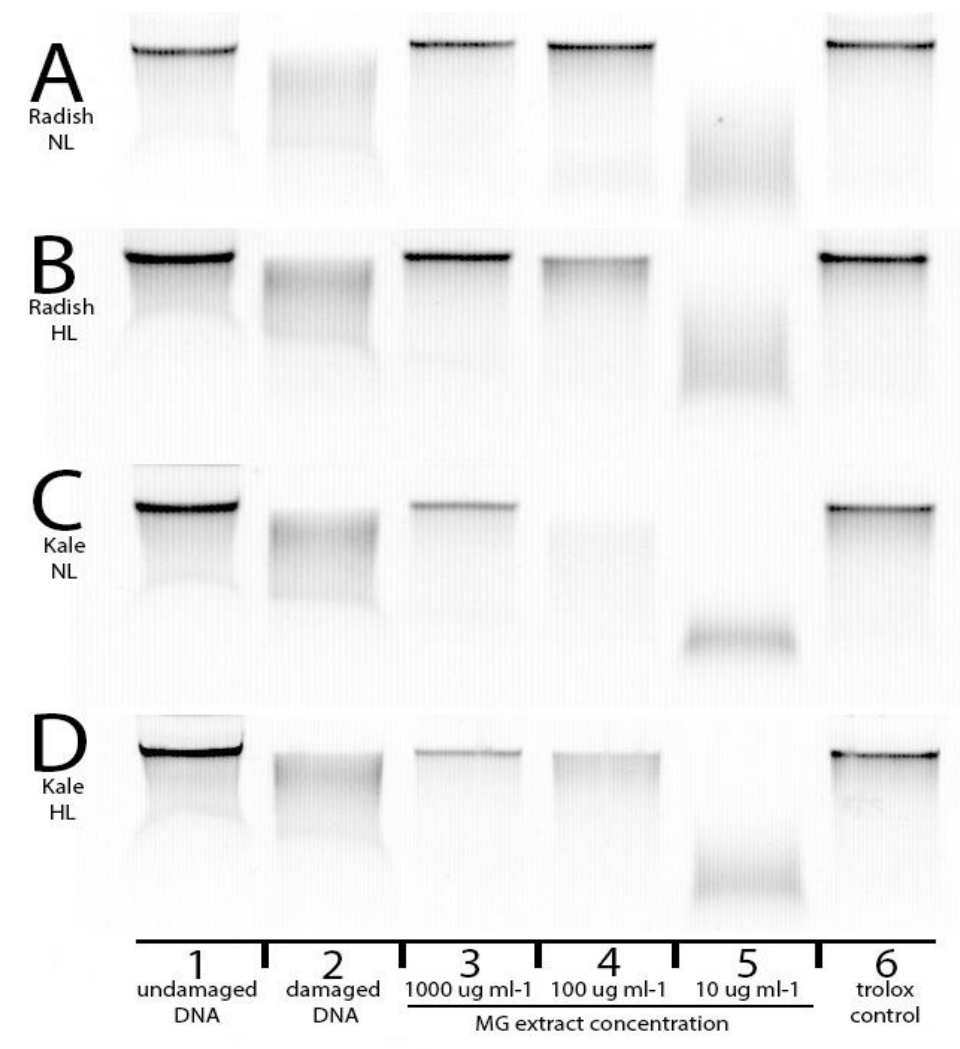

Figure 5: DNA damage/protection assays compared between radish and kale MGs propagated under normal (A, radish and $\mathrm{C}$, kale) and high light (B, radish and $\mathrm{D}$, kale). Human genomic DNA was treated with Fenton's reagent to induce oxidative stress. Lane 1, undamaged DNA; Lane 2, damaged DNA; Lane 3 -5, DNA pre-treated with either 1000, 100 or $10 \mathrm{~g} \mathrm{ml} \mathrm{MG} \mathrm{extract}$ respectively; Lane 5, Trolox (control). NL, normal light; HL, high light.

\section{Comparison of phytochemicals accumulating in response to high light stress}

Tandem mass spectrometry analyses (LC-MS/MS) was conducted on extracts from radish and kale MGs to identify specific compounds and/or groups of compounds that accumulated in response to HL (compared to NL). The extracts from radish MGs grown under HL differentially accumulated (i) carbohydrates, (ii) coumarin and/or cinnamic acids, (iii) proanthocyanidins, and (iv) flavonoid glycosides (Table 1, Figure 6). The compounds were grouped according to their mass and structure predictions from which specific compounds for proanthocyanidins (Epigallocatechin-(4beta->8)epicatechin-3-O-gallate ester) and glucosinolates (4-Hydroxy-3-indolylmethylglucosinolate) were identified.

The extracts from kale MGs grown under HL differentially accumulated (i) phenolic acids, (ii) amino- and sulfated- carbohydrates, and (iii) flavonoids (Table 1, Figure 6). The compounds were grouped according to their mass and structure predictions from which specific compounds for flavonoids (3,5,7-Tris(acetyloxy)-2-[4-(acetyloxy)-3-hydroxyphenyl]-4H-1-benzopyran-4one), amino oligosaccharides (N-acetyl-D-galactosaminyl-(1->4)-(N-acetyl-D-galactosaminyl)(1->3)-N-acetyl-D-galactosaminitol) and carbohydrate sulfates (alpha-Neup5Ac-(2->3)-beta-DGalp-(1->3)-alpha-D-GalpNAc6S) were identified. 


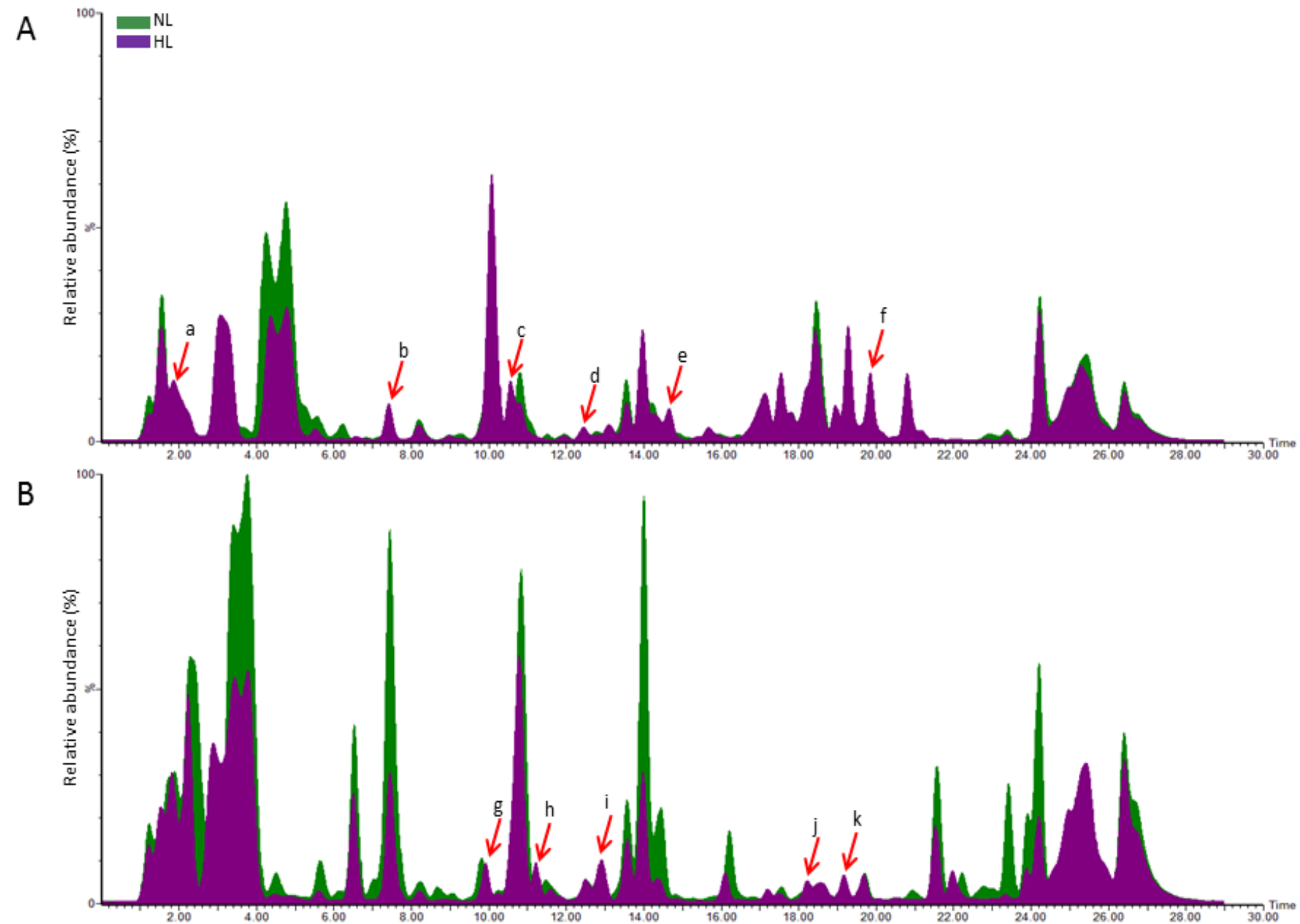

Figure 6: LC-MS/MS data indicating metabolic responses in (A) radish and (B) kale MGs grown under high light. The base peak ion chromatograms were extracted from each sample and overlaid to identify peaks (indicated by red arrows) that were present in HL (purple chromatogram) grown MGs, but absent in NL (green chromatogram) grown MGs. NL, normal light; HL, high light.

Table 1: Compounds in radish and kale MGs that accumulate as result of HL. Qualitative LCMS/MS was conducted to predict which compounds accumulate in MG tissue when grown under HL conditions. The $\mathrm{m} / \mathrm{z}$ spectrum was extracted from the respective peaks (refer to figure 6 ) and further used to confirm and/or predict known compounds accumulating as response to HL (a-k; using Metabolomics Workbench software).

\begin{tabular}{|c|c|c|c|c|c|}
\hline Peak & $\begin{array}{l}\text { Input mass } \\
(\mathbf{m} / \mathbf{z})\end{array}$ & $\begin{array}{l}\text { Formula } \\
\text { (neutral) }\end{array}$ & $\begin{array}{l}\text { Exact mass } \\
\text { (neutral) }\end{array}$ & Predicted Compound (s) & Compound class \\
\hline a & 341.1083 & $\mathrm{C}_{12} \mathrm{H}_{22} \mathrm{O}_{11}$ & 342.1162 & $\begin{array}{l}\text { - Galactinol } \\
\text { - Trehalose } \\
\text { - Mannobiose } \\
\text { - Kojibiose } \\
\text { - Sucrose } \\
\text { - Maltose }\end{array}$ & Carbohydrates \\
\hline
\end{tabular}




\begin{tabular}{|c|c|c|c|c|c|}
\hline $\mathrm{b}$ & 463.0487 & $\mathrm{C}_{16} \mathrm{H}_{20} \mathrm{~N}_{2} \mathrm{O}_{10} \mathrm{~S}_{2}$ & 464.0559 & $\begin{array}{l}\text { - } 4 \text {-Hydroxy-3- } \\
\text { indolylmethylglucosinolate }\end{array}$ & Glucosinolate \\
\hline $\mathrm{c}$ & 341.0878 & $\mathrm{C}_{15} \mathrm{H}_{18} \mathrm{O}_{9}$ & 342.0951 & $\begin{array}{ll}\text { - } & \text { 1-O-Caffeoylglucose } \\
\text { - } & \text { Caffeic acid 3-glucoside } \\
\text { - } & \text { Glucocaffeic acid }\end{array}$ & Glycoside \\
\hline $\mathrm{d}$ & 325.0915 & $\mathrm{C}_{15} \mathrm{H}_{18} \mathrm{O}_{8}$ & 326.1002 & $\begin{array}{ll}\text { - } & \text { 1-O-(4-coumaroyl)-beta-D- } \\
\text { glucose } \\
\text { - } \\
\text { 2-(beta-D-glucosyloxy)-cis- } \\
\text { cinnamic acid } \\
\text { - } 4 \text {-O-beta-D-glucosyl-4- } \\
\text { coumaric acid } \\
\text { - } 4 \text {-O-beta-D-glucosyl-cis-p- } \\
\text { coumaric acid } \\
\text { - } \text { Bilobalide } \\
\text { - } \text { trans-beta-D-glucosyl-2- } \\
\text { hydroxycinnamic } \\
\text { - trans-o-Coumaric acid 2- } \\
\text { glucoside }\end{array}$ & Terpene glucoside \\
\hline e & $\begin{array}{l}591.1005 \\
\text { (fragment } \\
\text { ion) }\end{array}$ & $\mathrm{C}_{37} \mathrm{H}_{30} \mathrm{O}_{17}$ & 746.1483 & $\begin{array}{l}\text { Epigallocatechin-(4beta->8)- } \\
\text { epicatechin-3-O-gallate ester }\end{array}$ & Proanthocyanidin \\
\hline $\mathrm{f}$ & 901.2430 & $\mathrm{C}_{42} \mathrm{H}_{46} \mathrm{O}_{22}$ & 902.2481 & $\begin{array}{l}\text { - } \text { Kaempferol O-glucoside } \\
\text { - } \text { Quercetin rhamnoside } \\
\text { - } \\
\text { - } \text { Isovitexin glucoside } \\
\text { Variabiloside C and D }\end{array}$ & Flavonoid \\
\hline $\mathrm{g}$ & 353.0846 & $\mathrm{C}_{16} \mathrm{H}_{18} \mathrm{O}_{9}$ & 354.0951 & $\begin{array}{l}\text { - } 5 Z-C a f f e o y l q u i n i c ~ a c i d \\
\text { - } \\
\text { - } \text { Biflorin } \\
\text { - } \text { Scoopologenic acid } \\
\text { - } \text { Trans-5-O-caffeoyl-D-quinic } \\
\text { - } \text { acid } \\
\text { - } \text { Trans-Chlorogenic acid } \\
\text { Cis-5-Caffeoylquinic acid }\end{array}$ & Phenolic acid \\
\hline $\mathrm{h}$ & $\begin{array}{l}371.0964 \\
\text { (fragment } \\
\text { ion) }\end{array}$ & $\mathrm{C}_{23} \mathrm{H}_{18} \mathrm{O}_{11}$ & 470.0849 & $\begin{array}{l}\text { 3,5,7-Tris(acetyloxy)-2-[4- } \\
\text { (acetyloxy)-3- } \\
\text { hydroxyphenyl]-4H-1- } \\
\text { benzopyran-4-one }\end{array}$ & Flavonoid \\
\hline $\mathrm{i}$ & 628.1627 & $\mathrm{C}_{24} \mathrm{H}_{43} \mathrm{~N}_{3} \mathrm{O}_{16}$ & 629.2643 & $\begin{array}{l}\text { N-acetyl-D-galactosaminyl- } \\
\text { (1->4)-(N-acetyl-D- } \\
\text { galactosaminyl)-(1->3)-N- } \\
\text { acetyl-D-galactosaminitol }\end{array}$ & Aminooligosaccharide \\
\hline $\mathrm{j}$ & 746.1956 & $\mathrm{C}_{34} \mathrm{H}_{35} \mathrm{O}_{19}$ & 747.1773 & $\begin{array}{l}\text { Cyanidin 3-(2G- } \\
\text { galloylrutinoside) } \\
\text { Cyanidin 3-O-(2"-O-galloyl- } \\
\text { 6"-O-alpha- } \\
\text { rhamnopyranosyl-beta- } \\
\text { galactopyranoside }\end{array}$ & Flavonoid \\
\hline $\mathrm{k}$ & 753.2256 & $\mathrm{C}_{25} \mathrm{H}_{42} \mathrm{~N}_{2} \mathrm{O}_{22}$ & 754.1950 & $\begin{array}{l}\text { alpha-Neup5Ac-(2->3)-beta- } \\
\text { D-Galp-(1->3)-alpha-D- } \\
\text { GalpNAc6S }\end{array}$ & Carbohydrate sulfate \\
\hline
\end{tabular}




\section{DISCUSSION}

Phytochemicals are associated with the health benefits of whole-plant based diets. A consumer market that seeks to include plants with enhanced phytochemical profiles has stimulated research efforts to (i) understand the metabolic fluxes during different developmental stages of plant growth (e.g. immature MG vs. mature), and (ii) develop effective bio-fortification strategies (using environmental stresses such as high light) to diversify phytochemical profiles. The recent interest and metabolite profiling of a range of MGs from Brassica species established their superior nutritional qualities over mature vegetables [20, 21, 28, 33]. Consequently, MGs have shifted from culinary garnish to health-promoting specialty crop. A major benefit of MG crops is the time it takes between planting and harvesting (approximately 10-25 days), resulting in a sustainable and steady supply of health beneficial plant-based foods rich in phytochemicals.

Although descriptive studies have inventoried the phytochemical profile of a range of MGs $[27,34]$, recent studies indicate a shift toward the understanding of how environmental biofortification strategies (light, temperature, water) could be used to diversify this profile [35, 36, 37]. During this early stage of development (MG), plants are exceptionally adaptable and respond rapidly to changes in their environment [38]. Exposure to HL is known to activate several stressresponsive pathways, including photosynthesis and redox signalling, resulting in altered carbon metabolism and energy balance [39, 40, 41, 42, 43]. Redox signalling causes increased levels of reactive oxygen species (ROS) in plant cells, which are toxic and can lead to severe cellular damage. A concomitant increase in phytochemicals is required as ROS scavengers (antioxidants) to protect the plant from oxidative damage $[44,45,46]$. In a previous study on wild rocket MGs, we demonstrated that HL bio-fortification resulted in the accumulation of resveratrol, a known ROS scavenger, and previously undocumented phytochemical in wild rocket [18]. Similarly, in this study, our objective was not to report on descriptive phytochemical profiling but rather to determine which phytochemicals uniquely appear in radish (root vegetable) and kale (leafy vegetable) MGs as a consequence of HL. By exploiting the increased ROS levels for the production of health beneficial phytochemicals (in planta), such bio-fortification techniques could be used in future to predictably diversify phytochemical profiles of MGs.

Phenotypic HL-induced responses include altered leaf and root morphogenesis as well as the inhibition of hypocotyl growth in both radish and kale MGs (Figure 1). Interestingly, radish initiated the development of a storage root, a phenomenon known as escape tropism, which allows roots to escape from unfavorable light conditions. This is well- known escape strategy used by mature plants and to our knowledge; this is the first report of such rapid production of storage roots in radish MGs. Furthermore, these radish 'micro-roots' displayed its typical red coloration. HL-exposed roots are associated with an increased phenylpropanoid metabolism [47], inducing the accumulation of flavonoids and anthocyanins (considered the most prominent color pigments in plants; Figure 6, Table 1). This type of phytochemical accumulation in the roots is important for stress adaptation, suggesting its role as a common intermediate in light signalling pathways to regulate root development $[48,49,50]$.

Several flavonoids are mediated by PAP transcription factors [51, 52, 53]. PAP-mediated pathways require sucrose, an energy resource that plants produce via photosynthesis. An upregulation of flavonoid production could, therefore, result in increased carbohydrate levels as a result of the careful regulation between sucrose and starch production during photosynthesis [54, $55,56]$. Increased total starch concentrations were observed for both radish and kale MGs 
suggesting that the redistribution and/or accumulation of carbohydrates are important physiological adaptations to HL (Figure 2). Fold-change increases in radish MG carbohydrates (including sucrose) further supports the idea that redistribution occurs, complementing the rapid production of storage 'micro-roots' (Figure 6, Table 1). Interestingly in kale MGs, the amino oligosaccharide and carbohydrate sulfate compounds are known to be triggered as part of defens e mechanisms, have also been upregulated [57, 58].

Such adaptations in the photosynthetic machinery have been well described and include redox signals arising from chloroplasts [59]. Ascorbic acid is known to accumulate in chloroplasts under HL conditions and believed to function as (i) photosystem electron donors, (ii) ROS scavengers, and (iii) co-factors to produce non-photochemical quenching metabolites [60]. Most Brassica vegetables are naturally rich in ascorbic acid, and it was surprising that kale MGs did not accumulate significantly more ascorbic acid in response to HL. Surprisingly, radish MGs accumulated significantly less ascorbic acid in response to HL (Figure 3). The production of ascorbic acid for ROS scavenging purposes during MG stage might either be (i) too taxing on the plant system or (ii) fully converted to other small molecules in its capacity as co-factor. It would be interesting to further investigate the regulatory mechanisms involving photosynthesis and ascorbic acid production in these MGs under HL. We speculate that radish and kale MGs rely largely on the upregulated phenylpropanoid pathway, producing a diverse array of phytochemicals to reduce the damage from oxidative stress.

Despite the unexpected effect of HL on ascorbic acid, the accumulation of phytochemicals collectively resulted in increased total antioxidant capacity (TAC) in both radish and kale MGs (Figure 4). Increased ROS production is compensated for by the increased phytochemical production, which collectively functions as an antioxidant system [61]. Rather than a description of all accumulated phytochemicals, our study purposely focused on tentative identification of phytochemicals that differentially accumulated in response to HL (Figure 6, Table 1). In radish, the major groups of phytochemicals included glucosinolates, flavonoid glycosides, terpene glucosides, proanthocyanidins and flavonoids (Table 1). All these groups have been directly or indirectly implicated in plant responses to light stress [53, 61]. The only glucosinolate that accumulated in response to HL was 4-hydroxy-3-methyl glucosinolate. Oxidative stress studies, using methyl jasmonate, in Arabidopsis and pak choi (Brassica rapa) resulted in enhanced accumulation of 3-indolyl-methyl-glucosinolates [62, 63]. Interestingly, the use of salicylic acid (inhibitor of jasmonate signalling) indicated a differential upregulation of 4-hydroxy-3-methyl glucosinolate implicating the importance of this compound in stress response mechanisms of Brassica $[62,64]$. Furthermore, the accumulation of a proanthocyanidin (epigallocatechin-(4beta>8)-epicatechin-3-O-gallate ester), commonly found in green tea, was also identified in radish MGs and is well described as a stress response compound in plants [1, 65]. In kale, the major groups of phytochemicals included flavonoids and phenolic acids, which include organic and chlorogenic acids (CGAs). One of the most abundant polyphenols included in the human diet is CGA, which has several important roles in the therapeutic properties of many plant extracts, such as antioxidant activity. Collectively, all these groups have, to some extent, shown to confer antioxidant capacity (in both humans and plants), and some studies have demonstrated effectiveness in disease (i.e. cardiovascular, diabetes, obesity) prevention [2, 66, 67].

Despite the existence of several assays measuring antioxidant capacity in plants and plant extracts [68], the TAC kit used in this study (based on the copper-reducing antioxidant capacity 
method or CUPRAC) has the ability to measure the non-enzymatic TAC of biological samples, indicating their ability to counteract oxidative stress-induced damage in cells. Validation of this TAC in MG extracts included the use of Fenton's reagent to demonstrate how extracts from the radish and kale MGs could protect DNA from the oxidative damage incurred by $\mathrm{H}_{2} \mathrm{O}_{2}$ (Figure 5). Extracts from both radish and kale MGs were equally effective at protecting DNA from oxidative damage at the highest concentration and exhibited no DNA protection at the lowest concentration, regardless of growing conditions. Comparatively, at concentrations of $100 \mathrm{~g} \mathrm{ml}^{-1}$ radish MG extracts, grown under NL, exhibited the most effective DNA protection ability. The ascorbic acid concentrations were highest in radish MGs grown under NL and it is interesting to speculate that the concomitant DNA protection could be due to ascorbic acid. Ascorbic acid is a non-enzymatic, water soluble antioxidant obtained from the diet and essential to humans because of its role in several physiological activities [69]. The antioxidant activity of ascorbic acid has been demonstrated to prevent the development of certain types of cancer, cardiovascular diseases and other illnesses related to oxidative stress [70,71]. Furthermore, ascorbic acid can convert reactive compounds to less toxic and more easily excreted products, as well as capturing free radicals before they interact with other molecules, protecting them from oxidative damage [72, 73]. However, many of these in vitro and in vivo studies are inconclusive, and it is suggested that compounds work synergistically (as a holistic antioxidant system).

In conclusion, the purpose of this study was to investigate the effects of HL on phytochemical accumulation and TAC in radish and kale MGs. Humans rely on a diverse array of vitamins, minerals, and phytochemicals for general and preventative health purposes, the latter of which are obtained solely from plant-based foods. Functional plant-based foods and food products contain abundant amounts of health-beneficial phytochemicals, which provides enhanced antioxidant capacity to prevent diseases associated with oxidative damage. MGs are known to contain up to 100 times more phytochemicals than mature plants, and it is proposed as an effective health beneficial speciality crop in the current global state of malnutrition, climate variability, and the availability of arable land. Such nutritious and phytochemical-rich speciality crops could be farmed (and bio-fortified simultaneously) vertically in controlled conditions, reducing the time from farm-to-table. Further enhancement and diversification of MG profiles through HL biofortification will ensure not only a resourceful fresh-food product but also a strategy for making dried supplemental products which could be used to fortify other food sources with a longer shelf life (such as bread, maize meal) as a means to human health and nutrition.

\section{List of abbreviations}

CGA - chlorogenic acid

CUPRAC - cupric reducing antioxidant capacity

DW - dry weight

$\mathrm{HL}$ - high light

LC-MS/MS - liquid chromatography mass spectrometry

$\mathrm{MG}$ - micro-greens

$\mathrm{NL}$ - normal light

ROS - reactive oxygen species

TAC - total antioxidant capacity 


\section{Competing interests: None}

\section{Author contributions}

AX and conducted metabolite extractions, ascorbic acid and TAC assays, and conducted DNA damage/protection assays. PM assisted with DNA damage assays as part of a learner programme. MS executed LC-MS/MS experiments and EH analysed LC-MS/MS data. NK executed starch assays. BL conceived of the project, interpreted the work and wrote the manuscript. SP actively provided valuable intellectual input and assisted in the writing of manuscript. JK provided infrastructure and funding toward the project.

\section{Acknowledgements and Funding}

This research was funded by the South African Research Chairs Initiative (SARChI), hosted by the South African National Research Foundation (NRF).

\section{REFERENCES:}

1. Chobot V, Huber C, Trettenhahn G, Hadacek F. (+/-)-catechin: chemical weapon, antioxidant, or stress regulator? Journal of Chemical Ecology. 2009;35(8):980-96.

2. Horáková L. Flavonoids in prevention of diseases with respect to modulation of Ca-pump function. Interdisciplinary Toxicology. 2011;4(3):114-24.

3. Ganesan K, Xu B. A critical review on polyphenols and health benefits of black soybeans. Nutrients. 2017;9(5):455.

4. Cory H, Passarelli S, Szeto J, Tamez M, Mattei J. The role of polyphenols in human health and food systems: A Mini-Review. Frontiers Nutrition. 2018;5:87.

5. Barba FJ, Nikmaram N, Roohinejad S, Khelfa A, Zhu Z, Koubaa M. Bioavailability of glucosinolates and their breakdown products: Impact of processing. Frontiers Nutrition. 2016;3:24.

6. Traka MH. Chapter Nine - Health Benefits of Glucosinolates. In: Kopriva S, editor. Advances in Botanical Research. 80: Academic Press; 2016. p. 247-79.

7. Tham DM, Gardner CD, Haskell WL. Potential Health Benefits of Dietary Phytoestrogens: A Review of the Clinical, Epidemiological, and Mechanistic Evidence1. The Journal of Clinical Endocrinology and Metabolism. 1998;83(7):2223-35.

8. Cornwell T, Cohick W, Raskin I. Dietary phytoestrogens and health. Phytochemistry. 2004;65(8):995-1016.

9. Rietjens IMCM, Louisse J, Beekmann K. The potential health effects of dietary phytoestrogens. Br J Pharmacol. 2017;174(11):1263-80.

10. Fiedor J, Burda K. Potential role of carotenoids as antioxidants in human health and disease. Nutrients. 2014;6(2):466-88.

11. Eggersdorfer M, Wyss A. Carotenoids in human nutrition and health. Archives of Biochemistry and Biophysics. 2018;652:18-26.

12. Machado RMA, Alves-Pereira I, Ferreira RMA. Plant growth, phytochemical accumulation and antioxidant activity of substrate-grown spinach. Heliyon. 2018;4(8):e00751-e.

13. Yang L, Wen K-S, Ruan X, Zhao Y-X, Wei F, Wang Q. Response of plant secondary metabolites to environmental factors. Molecules. 2018;23(4):762. 
14. Forni C, Facchiano F, Bartoli M, Pieretti S, Facchiano A, D'Arcangelo D, et al. Beneficial role of phytochemicals on oxidative stress and age-related diseases. BioMed Research International. 2019;2019:16.

15. Terry P, Wolk A, Persson I, Magnusson C. Brassica vegetables and breast cancer risk. The Journal of the American Medical Association. 2001;285(23):2975-7.

16. Higdon JV, Delage B, Williams DE, Dashwood RH. Cruciferous vegetables and human cancer risk: epidemiologic evidence and mechanistic basis. Pharmacological Research. 2007;55(3):224-36.

17. Kellingray L, Tapp HS, Saha S, Doleman JF, Narbad A, Mithen RF. Consumption of a diet rich in Brassica vegetables is associated with a reduced abundance of sulphate-reducing bacteria:A randomised cross-over study. Molecular Nutritional Food Research. 2017,61(9).

18. Loedolff B, Brooks J, Stander M, Peters S, Kossmann J. High light bio-fortification stimulates de novo synthesis of resveratrol in Diplotaxis tenuifolia (wild rocket) microgreens. Functional Foods in Health and Disease. 2017; 7(11),859-872.

19. Vaštakaitė V, Viršilė A, Brazaitytė A, Samuolienė G, Jankauskienė J, Novičkovas A, et al. Pulsed Light-Emitting Diodes for a Higher Phytochemical Level in Microgreens. Journal of Agricultural and Food Chemistry. 2017;65(31):6529-34.

20. Kyriacou MC, Rouphael Y, Di Gioia F, Kyratzis A, Serio F, Renna M, et al. Micro-scale vegetable production and the rise of microgreens. Trends in Food Science and Technology. 2016;57:103-15.

21. Kyriacou MC, De Pascale S, Kyratzis A, Rouphael Y. Microgreens as a component of space life support systems: A cornucopia of functional food. Frontiers in Plant Science. 2017;8(1587).

22. Neumann PM. Coping Mechanisms for Crop Plants in Drought-prone Environments. Annals of Botany. 2008;101(7):901-7.

23. Biswal B, Joshi PN, Raval MK, Biswal UC. Photosynthesis, a global sensor of environmental stress in green plants: stress signalling and adaptation. Current Science. 2011;101(1):47-56.

24. Egert A, Eicher B, Keller F, Peters S. Evidence for water deficit-induced mass increases of raffinose family oligosaccharides (RFOs) in the leaves of three Craterostigma resurrection plant species. Frontiers in Physiology. 2015;6(206).

25. Rouached H, Pal S, Rachmilevitch S, Libault M, Tran L-SP. Plants coping abiotic and biotic stresses: a tale of diligent management. BioMed research international. 2015;2015:754754.

26. Khan A, Pan X, Najeeb U, Tan DKY, Fahad S, Zahoor R, et al. Coping with drought: stress and adaptive mechanisms, and management through cultural and molecular alternatives in cotton as vital constituents for plant stress resilience and fitness. Biological Research. 2018;51(1):47.

27. Xiao Z, Codling EE, Luo Y, Nou X, Lester GE, Wang Q. Microgreens of Brassicaceae: Mineral composition and content of 30 varieties. Journal of Food Composition and Analysis. 2016;49:87-93.

28. Riggio GM, Wang Q, Kniel KE, Gibson KE. Microgreens-A review of food safety considerations along the farm to fork continuum. International Journal of Food 
Microbiology. 2019;290:76-85.

29. Routaboul JM, Kerhoas L, Debeaujon I. et al. (2006) Flavonoid diversity and biosynthesis in seed of Arabidopsis thaliana. Planta 224: 96.

30. Peters S, Mundree SG, Thomson JA, Farrant JM, Keller F. Protection mechanisms in the resurrection plant Xerophyta viscosa (Baker): both sucrose and raffinose family oligosaccharides (RFOs) accumulate in leaves in response to water deficit. Journal of Experimental Botany. 2007;58(8):1947-56.

31. Jiang Y, Han W, Shen T, Wang M-H. Antioxidant activity and protection from DNA damage by water extract from pine (Pinus densiflora) Bark. Preventive Nutrition and Food Science. 2012;17(2):116-21.

32. Sud M, Fahy E, Cotter D, Azam K, Vadivelu I, Burant C, et al. Metabolomics Workbench: An international repository for metabolomics data and metadata, metabolite standards, protocols, tutorials and training, and analysis tools. Nucleic Acids Research. 2016;44(D1):D463-D70.

33. Allegretta I, Gattullo CE, Renna M, Paradiso VM, Terzano R. Rapid multi-element characterization of microgreens via total-reflection X-ray fluorescence (TXRF) spectrometry. Food Chemistry. 2019;296:86-93.

34. Pinto E, Almeida AA, Aguiar AA, Ferreira I. Comparison between the mineral profile and nitrate content of microgreens and mature lettuces. Journal of Food Composition and Analysis. 2015;37:38-43.

35. Kushad MM, Brown AF, Kurilich AC, Juvik JA, Klein BP, Wallig MA, et al. Variation of glucosinolates in vegetable crops of Brassica oleracea. Journal of Agricultural and Food Chemistry. 1999;47(4):1541-8.

36. Samuolien ÄG, Brazaityt ÄA, Sirtautas R, Sakalauskien ÄS, Jankauskien ÄJ, Duchovskis $\mathrm{P}$, et al., editors. The impact of supplementary short-term red led lighting on the antioxidant properties of microgreens 2012: International Society for Horticultural Science (ISHS), Leuven, Belgium.

37. Craver JK, Gerovac JR, Lopez RG, Kopsell DA. Light intensity and light quality from sole-source light-emitting diodes impact phytochemical concentrations within Brassica microgreens. 2017;142(1):3.

38. Suzuki N, Koussevitzky S, Mittler R, Miller G. ROS and redox signalling in the response of plants to abiotic stress. Plant, Cell and Environment. 2012;35(2):259-70.

39. Shulaev V, Cortes D, Miller G, Mittler R. Metabolomics for plant stress response. Physiologia Plantarum. 2008;132(2):199-208.

40. Wilhelm C, Selmar D. Energy dissipation is an essential mechanism to sustain the viability of plants: The physiological limits of improved photosynthesis. Journal of Plant Physiology. 2011;168(2):79-87.

41. Hazrati S, Tahmasebi-Sarvestani Z, Modarres-Sanavy SAM, Mokhtassi-Bidgoli A, Nicola S. Effects of water stress and light intensity on chlorophyll fluorescence parameters and pigments of Aloe vera L. Plant Physiology and Biochemistry. 2016;106:141-8.

42. Gu J, Zhou Z, Li Z, Chen Y, Wang Z, Zhang H, et al. Photosynthetic properties and potentials for improvement of photosynthesis in pale green leaf rice under high light conditions. Frontiers in Plant Science. 2017;8:1082.

43. Loedolff B, van der Vyver C (2019) Water Stress and Redox Regulation with Emphasis on 
Future Biotechnological Prospects. In: Panda S., Yamamoto Y. (eds) Redox Homeostasis in Plants. Signalling and Communication in Plants. Springer, Cham

44. Dat JF, Lopez-Delgado H, Foyer CH, Scott IM. Effects of salicylic acid on oxidative stress and thermotolerance in Tobacco. Journal of Plant Physiology. 2000;156(5):659-65.

45. Vranová E, Inzé D, Van Breusegem F. Signal transduction during oxidative stress. Journal of Experimental Botany. 2002;53(372):1227-36.

46. Li M, Li X, Han C, Ji N, Jin P, Zheng Y. UV-C treatment maintains quality and enhances antioxidant capacity of fresh-cut strawberries. Postharvest Biology and Technology. 2019;156:110945.

47. Hemm MR, Rider SD, Ogas J, Murry DJ, Chapple C. Light induces phenylpropanoid metabolism in Arabidopsis roots. The Plant Journal. 2004;38(5):765-78.

48. Buer CS, Muday GK. The transparent testa4 mutation prevents flavonoid synthesis and alters auxin transport and the response of Arabidopsis roots to gravity and light. Plant Cell. 2004;16(5):1191-205.

49. Agati G, Biricolti S, Guidi L, Ferrini F, Fini A, Tattini M. The biosynthesis of flavonoids is enhanced similarly by UV radiation and root zone salinity in L. vulgare leaves. Journal of Plant Physiology. 2011;168(3):204-12.

50. Schäffner AR. Flavonoid biosynthesis and Arabidopsis genetics: more good music. Journal of experimental botany. 2016;67(5):1203-4.

51. Zhai R, Wang Z, Zhang S, Meng G, Song L, Wang Z, et al. Two MYB transcription factors regulate flavonoid biosynthesis in pear fruit (Pyrus bretschneideri Rehd.). Journal of Experimental Botany. 2015;67(5):1275-84.

52. Mouradov A, Spangenberg G. Flavonoids: a metabolic network mediating plants adaptation to their real estate. Frontiers in Plant Science. 2014;5(620).

53. Outchkourov NS, Karlova R, Hölscher M, Schrama X, Blilou I, Jongedijk E, et al. Transcription Factor-Mediated Control of Anthocyanin Biosynthesis in Vegetative Tissues. Plant Physiology. 2018;176(2):1862.

54. Nott A, Jung H-S, Koussevitzky S, Chory J. Plastid-to-nucleus retrograde signaling. Annual Review of Plant Biology. 2006;57(1):739-59.

55. Piippo M, Allahverdiyeva Y, Paakkarinen V, Suoranta U-M, Battchikova N, Aro E-M. Chloroplast-mediated regulation of nuclear genes in Arabidopsis thaliana in the absence of light stress. Physiological Genomics. 2006;25(1):142-52.

56. Bräutigam K, Dietzel L, Kleine T, Ströher E, Wormuth D, Dietz K-J, et al. Dynamic plastid redox signals integrate gene expression and metabolism to induce distinct metabolic states in photosynthetic acclimation in Arabidopsis. Plant Cell. 2009;21(9):2715.

57. Obata T, Fernie AR. The use of metabolomics to dissect plant responses to abiotic stresses. Cellular and Molecular Life Sciences. 2012;69(19):3225-43.

58. Kumar M, Padula MP, Davey P, Pernice M, Jiang Z, Sablok G, et al. Proteome analysis reveals extensive light stress-response reprogramming in the seagrass Zostera muelleri (Alismatales, Zosteraceae) metabolism. Frontiers in Plant Science. 2017;7(2023).

59. Baier M, Dietz K-J. Chloroplasts as source and target of cellular redox regulation: a discussion on chloroplast redox signals in the context of plant physiology. Journal of Experimental Botany. 2005;56(416):1449-62.

60. Suzuki N, Mittler R. Reactive oxygen species and temperature stresses: A delicate balance 
between signaling and destruction. Physiologia Plantarum. 2006;126(1):45-51.

61. Mittler R, Vanderauwera S, Gollery M, Van Breusegem F. Reactive oxygen gene network of plants. Trends in Plant Science. 2004;9(10):490-8.

62. Mikkelsen BL, Rosendahl S, Jakobsen I. Underground resource allocation between individual networks of mycorrhizal fungi. New Phytologist. 2008;180(4):890-8.

63. Wiesner C, El Azzouzi K, Linder S. A specific subset of RabGTPases controls cell surface exposure of MT1-MMP, extracellular matrix degradation and three-dimensional invasion of macrophages. Journal of Cell Science. 2013;126(13):2820.

64. Mikkelsen MD, Naur P, Halkier BA. Arabidopsis mutants in the C-S lyase of glucosinolate biosynthesis establish a critical role for indole-3-acetaldoxime in auxin homeostasis. The Plant Journal. 2004;37(5):770-7.

65. Bernatoniene J, Kopustinskiene DM. The role of catechins in cellular responses to oxidative stress. Molecules. 2018;23(4):965.

66. Naveed M, Hejazi V, Abbas M, Kamboh AA, Khan GJ, Shumzaid M, et al. Chlorogenic acid (CGA): A pharmacological review and call for further research. Biomedicine \& Pharmacotherapy. 2018;97:67-74.

67. Sung S, Kwon D, Um E, Kim B. Could Polyphenols Help in the Control of Rheumatoid Arthritis? Molecules. 2019;24(8):1589.

68. Trofin AE, Trinca LC, Ungureanu E, Ariton AM. CUPRAC Voltammetric Determination of Antioxidant Capacity in Tea Samples by Using Screen-Printed Microelectrodes. Journal of Analytical Methods in Chemistry. 2019;2019:10.

69. Sram RJ, Binkova B, Rossner P. Vitamin C for DNA damage prevention. Mutation Research/Fundamental and Molecular Mechanisms of Mutagenesis. 2012;733(1):39-49.

70. Hemilä H, Chalker E, Douglas B. Vitamin C for preventing and treating the common cold. Cochrane Database of Systematic Reviews. 2007(3).

71. Castelo-Branco PV, Alves HJ, Pontes RL, Maciel-Silva VL, Ferreira Pereira SR. Ascorbic acid reduces the genetic damage caused by miltefosine (hexadecylphosphocholine) in animals infected by Leishmania (Leishamnia) infantum without decreasing its antileishmanial activity. International Journal for Parasitology: Drugs and Drug Resistance. 2019;9:8-15.

72. Li P, Shen Z, Wang W, Ma Z, Bi S, Sun H, et al. The capture of 'H and ' OH radicals by vitamin $\mathrm{C}$ and implications for the new source for the formation of the anion free radical. Physical Chemistry Chemical Physics. 2010; 12(20):5256-67.

73. Yimcharoen M, Kittikunnathum S, Suknikorn C, Nak-on W, Yeethong P, Anthony TG, et al. Effects of ascorbic acid supplementation on oxidative stress markers in healthy women following a single bout of exercise. Journal of the International Society of Sports Nutrition. 2019;16(1):2. 